\title{
Chromatographic Characterization and Process Performance of Column-Packed Anion Exchange Fibrous Adsorbents for High Throughput and High Capacity Bioseparations
}

\section{Poondi Rajesh Gavara ${ }^{1, *}$, Noor Shad Bibi ${ }^{2}$, Mirna Lorena Sanchez ${ }^{3}$, Mariano Grasselli ${ }^{3}$ and Marcelo Fernandez-Lahore ${ }^{2, *}$}

1 Chipro GmbH, Anne-Conway-Strasse.1, D-28359 Bremen, Germany

2 Downstream Processing Laboratory, Jacobs University, Campus Ring 1, D-28759 Bremen, Germany; E-Mail: noor_362@yahoo.com

3 Laboratorio de Materiales Biotecnológicos, Depto. de Ciencia y Tecnología, Universidad Nacional de Quilmes-IMBICE (CONICET),

Roque Sáenz Peña 352 (B1876BXD) Bernal, Argentina;

E-Mails: mirnalorenasanchez@gmail.com (M.L.S.); mariano.grasselli@gmail.com (M.G.)

* Authors to whom correspondence should be addressed;

E-Mails: rgavara@chipro.de (P.R.G.); m.fernandez-lahore@jacobs-university.de (M.F.-L.); Tel.: +49-421-200-3239 (M.F.-L.); Fax: +49-421-200-3600 (M.F.-L.).

Academic Editor: Kostas A. Matis

Received: 21 January 2015 / Accepted: 10 March 2015 / Published: 20 March 2015

\begin{abstract}
Fibrous materials are prominent among novel chromatographic supports for the separation and purification of biomolecules. In this work, strong anion exchange, quaternary ammonium (Q) functional fibrous adsorbents were evaluated with regards to their physical and functional characteristics. A column packed with Q fibrous adsorbent illustrated the good column packing efficiency of theoretical plate height $(\mathrm{H})$ values and higher permeability coefficients $\left(>0.9 \times 10^{-7} \mathrm{~cm}^{2}\right)$ than commercial adsorbents. For pulse experiments with acetone and lactoferrin as tracers under nonbinding conditions, the total porosity (for acetone) and the interstitial porosity (for lactoferrin) measured 0.97 and 0.47 , respectively. The total ionic capacity of the chemically-functionalized $\mathrm{Q}$ fiber was $0.51 \mathrm{mmol} / \mathrm{mL}$. The results indicated that the $\mathrm{Q}$ fiber had a static binding capacity of $140 \mathrm{mg} / \mathrm{mL}$ and a dynamic binding capacity (DBC) of $76 \mathrm{mg} / \mathrm{mL}$ for bovine serum albumin (BSA) and showed a linearly-scalable factor $(\sim 110 \mathrm{~mL})$ for a column volume with high capacity and high throughput. Furthermore, this adsorptive material had the ability to bind
\end{abstract}


the high molecular weight protein, thyroglobulin, with a capacity of $6 \mathrm{mg} / \mathrm{mL}$. This work demonstrated the column-packed Q fibrous adsorption system as a potential chromatography support that exhibits high capacity at higher flow rates.

Keywords: fibrous adsorbent; column packing; permeability coefficient; dynamic binding capacity

\section{Introduction}

Industrial biotherapeutic product isolation and purification processes are carried out by a conventional downstream process that typically involves a cascade of unit operations, including cell harvest, product capture, purification, polishing and formulation. These operations of downstream processing exhibit low capacity and low throughput; they are labor intensive and require large hold-up volumes to run in batch or semi-batch mode and usually account for $50 \%-80 \%$ of the production costs of drug substances [1-7]. Consequently, the biopharmaceutical industry has begun to target process intensification and integration to improve economics by linking two or more separation schemes into one, thereby decreasing production time, cost of goods and capital investments [8-11]. The bulk of industrial-scale capture and purification steps for biological molecules is carried out in chromatographic packed-bed adsorption columns with porous beads that have ion-exchange or affinity ligand functionalities $[12,13]$. Even though packed-bead operations provide excellent separation and resolution capabilities, the column chromatographic process suffers from the low dynamic binding capacity of the beads to capture the target product and the relatively large pressure drop due to high operational flow rates. The unfavorable flow channeling and poor dispersion within the packed bed make it difficult to pack and scale up bead-based chromatography. All of this eventually leads to high material and operational costs [14-16].

As a consequence, the industrial purification processes requires innovative and cost-effective alternative materials to replace traditional packed column resins [16-21]. One such material is fabric derived from coupled synthetic nylon, polypropylene and PES (polyethersulfone) [22]. These fibrous substrates exhibit various advantages with regard to high surface area and variable and controllable porosity that enable high swelling capacities and higher liquid flow rates with excellent mechanical and chemical stability [23]. They have been widely utilized for the extraction of analytes and the separation of trace elements [24-26] and have also been applied in the production of recombinant proteins [27,28], due to biocompatibility and the inexpensiveness of the raw material production cost. Numerous methods of graft polymerization techniques, like chemical initiation, ultraviolet light, cold plasma, electron beam and gamma rays [29-37], have been utilized for surface activation of epoxy groups on fabric substrates, like nylon, polypropylene, poly(alginic acid) and cotton fibers [38]. They also facilitate subsequent appropriate functional ligand immobilization and act as a chromatography adsorbent. However, these materials have not been reported for high throughput and high capacity, due to low porosity, lack of a hydrogel structure, irregular packing and low pressure drop for process-scale bioseparation [39,40]. Surface grafting for the activation of membrane fabrics as an alternative cotton fabric showed low throughput and low dynamic binding capacity for bioseparation applications [34,41-43]. In recent years, Gavara et al. [20] have successfully demonstrated a novel composite fiber with internal ligand 
immobilization for potential use as a cation exchange fiber-based material for the separation and purification of biomolecules.

In this paper, an anion exchange fibrous material containing trimethyl ammonium ligand (Q fibers) in a column-packed form was analyzed for chromatographic performances. Adsorptive fibers have a modified hydrogen bond network with positively-charged functional moieties, on the one hand [44], and increased protein loading by electrostatic interactions, on the other $[45,46]$. The anion exchange fibrous adsorbent was prepared according to the previously described procedure $[20,47]$ and investigated by a plethora of physico-chemical and functional characteristics. The functionalized fibers were oriented in a randomly-packed form in linearly-scalable columns. Additionally, the quality of the packing efficiency and pressure drop was evaluated. The interstitial and total porosities and permeability of the fibrous adsorbent were also measured. For the column characteristics of the packed fibers, breakthrough analyses have been determined for operation in the frontal mode and were also compared to the effect of the molecular weight of the protein on the dynamic binding capacity (DBC). This is the first research work that describes the performance of the column-packed fibers as a chromatography media that could be scalable for a 1 - to $110-\mathrm{mL}$ column volume.

\section{Experimental Materials and Methods}

\subsection{Materials}

Natural cotton material used in this research was purchased from Gebrüder Otto $\mathrm{GmbH} \& \mathrm{Co} . \mathrm{Kg}$ (Dietenheim, Germany). Fiber diameters ranged 1-20 $\mu \mathrm{m}$, and the surface textures of the fiber were qualitatively analyzed using scanning electron microscope (SEM) images. BSA was purchased from Sigma-Aldrich Chemie GmbH (Steinheim, Germany). Acetone was procured from AppliChem GmbH (Darmstadt, Germany). A QF150 biotech pump was purchased from (Quattroflow Fluid Systems, Hardegsen, Germany). Chromatography columns, Tricorn 5/50 (0.5 mm internal diameter (ID) $\times 5.5 \mathrm{~cm}$ length $(\mathrm{L}))$, XK $50(50 \mathrm{~mm}$ ID $\times 20 \mathrm{~cm} \mathrm{~L})$, Q Sepharose FF resin and the ÄKTA explorer system equipped with Unicorn 4.10 software for data collection and analysis were obtained from GE Healthcare (Uppsala, Sweden). All of the buffer solutions were filtered with $0.45-\mu \mathrm{m}$ filter (Sartorius, Goettingen, Germany).

\subsection{Physico-Chemical Characterization}

\subsubsection{Swelling and Porosity}

The percentage degree of swelling $(\% \mathrm{DS})$ was estimated by weighing the fiber sample in the wet state $\left(m_{w e t}\right)$ and after drying $\left(m_{d r y}\right)$ to a constant weight at $50{ }^{\circ} \mathrm{C}$ under a vacuum in a drier, as shown in Equation (1).

$$
\% \mathrm{DS}(\mathrm{g} \text { per } \mathrm{g})=\left(m_{\mathrm{wet}}-m_{\text {dry }}\right) /\left(m_{\text {dry }}\right)
$$

The total volume of pores (porosity, expressed as \%) within the fibrous material body was measured by the water uptake of the "squeezed" swollen sample using Equation (2) [20,48], where $1 \mathrm{~g}$ of fibrous adsorbents was immersed in deionized water for an hour; $m_{\text {swollen }}$ is the mass of the material after water 
uptake, and $m_{\text {water-bound }}$ is the mass of the dry material once it has gained bound water by absorption of water vapor.

$$
\text { Porosity }(\%)=\left[\left(m_{\text {swollen }}-m_{\text {water-bound }}\right) / m_{\text {swollen }}\right] \times 100
$$

\subsubsection{Microscopy}

The adsorptive fibers and virgin cellulose fibers were preconditioned in $3 \mathrm{M} \mathrm{KCl}$ in a phosphate buffer and wetted with distilled water. Finally, the samples were dried at $50{ }^{\circ} \mathrm{C}$ in an oven, and then gold sputtered samples were examined at different magnifications using a Joel JSM 5900 (JOEL USA, Inc.: Peabody, MA, USA) scanning electron microscope (SEM). The morphology of the modified Q fibers after protein adsorption was visualized using confocal laser scanning microscopy (CLSM). Zero-point-zero one grams of Q fiber samples were incubated with a BSA-labeled Alexa Fluor 488 (green dye) in $0.1 \mathrm{M}$ sodium phosphate with a $\mathrm{pH}$ of 7.4 , for $2 \mathrm{~h}$ at room temperature on a rotor. After this, the samples were thoroughly washed with a conditioned buffer and then examined directly using confocal microscopy. Confocal images were taken utilizing a Carl ZeissLS510 (AxioVision version 3.0; Carl Zeiss, Inc.: Thornwood, NY, USA). The resulting pictures were collected using the laser excitation sources at $488 \mathrm{~nm}$ [20].

\subsection{Functional Characterization}

\subsubsection{Column Packing}

The dried anion exchanger fibrous adsorbent was homogenized into relatively short fibers $(<1 \mathrm{~cm})$ using an electric mixer (McMaster-Carr, Aurora, CO, USA) at a constant interval of time (1 to $1.5 \mathrm{~min}$ ) and speed $(50 \mathrm{rpm})$. Zero-point-two grams of functionalized adsorbent were randomly packed into a Tricorn 5/50 mm column of a 1-mL column volume. The packed fabric bed was then swollen in place with $20 \mathrm{mM}$ Tris-HCl buffer ( $\mathrm{pH} 7.4)$ at a low flow velocity $(\sim 75 \mathrm{~cm} / \mathrm{h})$, and the bed height of the column was re-adjusted, so that there was no free headspace in the column after the swelling of the medium contained in the functionalized material [20]. The bed height was $5.5 \mathrm{~cm}$, and the column volume was $1 \mathrm{~mL}$. The same procedure was applied to the packing of XK 50 column, keeping the same bed height $(5.5 \mathrm{~cm})$ and the column volume of $\sim 108 \mathrm{~mL}$. The quality of column packing efficiency was evaluated in terms of the plate height by impulse injection experiments using acetone of $5.0 \%(v / v)$ as the tracer under a non-retained condition at flow velocities ranging from 75 to $600 \mathrm{~cm} / \mathrm{h}$.

\subsubsection{Pulse Experiments}

The packed Tricorn 5/50 and XK 50 columns were prepared for pulse experiments, which were conducted at room temperature on an ÄKTA explorer system with a sample loop and internal UV detector. Aqueous acetone of $5.0 \%(v / v)$ and lactoferrin solution of $10 \mathrm{mg} / \mathrm{mL}$ were injected in the amount of $1 \%$ column volume at different linear flow velocities between 75 and $600 \mathrm{~cm} / \mathrm{h}$ with Tris-HCl buffer. The extra-column volume was accounted for by conducting the same measurements, bypassing the fibrous column in the system. 


\subsubsection{Flow Permeability Experiments}

The pressure drop along the length of columns (Tricorn 5/50 and XK 50) packed with Q fibrous adsorbent was measured at four different flow velocities between 75 and $600 \mathrm{~cm} / \mathrm{h}$ using $20 \mathrm{mM}$ phosphate buffer ( $\mathrm{pH}$ 7.4). The aforementioned packed columns were mounted on the ÄKTA explorer system, and the flow permeability experiments were conducted at room temperature with internal and external digital pressure monitors. The measurements of pressure drop were determined by the difference in the pressure at the inlet and the outlet of the column observed in the pressure monitor. The extra-column pressure drop was accounted for by conducting the same measurements without a fibrous column. A QF150 biotech pump was used to control the linear flow velocity $(600 \mathrm{~cm} / \mathrm{h})$ for the XK50 column, as the ÄKTA explorer was not compatible with that flow velocity.

\subsubsection{Determination of the Ionic Capacity}

The ionic capacity (or phosphate capacity) of the porous adsorbents was determined by the transient $\mathrm{pH}$ phenomenon [49]. In this system, the ionic capacity was measured using two buffer solutions having the same $\mathrm{pH}$ value, but different ionic strengths. The packed anion exchange fibrous column was conditioned with $500 \mathrm{mM}$ phosphate $\mathrm{pH} 7.4$ (Buffer A) and then subsequently shifted to $20 \mathrm{mM}$ phosphate $\mathrm{pH} 7.4$ (Buffer B). The buffer switch induced a change in $\mathrm{pH}$ as a result of the release of ions that were bound to the adsorbent in the column during high salt conditions. The time interval $\Delta t(\mathrm{pH})$ was determined between the switching point of the mobile phase and the point at which $50 \%$ of the maximum $\mathrm{pH}$ value was achieved. The phosphate capacity was calculated using Equation (3), where the volumetric flow rate $\left(\phi_{\mathrm{v}}\right)$, concentration of elution buffer solution $\left(C_{2}\right)$, and column volume $(V c)$, as well as time interval $(\Delta t)$ are used in the expression [50,51]. Q Sepharose FF beads were utilized as a control ion exchange sample.

$$
K=\left[\left(\Delta t(\mathrm{pH})_{50 \%} \phi_{\mathrm{v}} C_{2}\right) / V_{\mathrm{c}}\right]
$$

\subsubsection{Protein Adsorption under Static and Dynamic Conditions}

Finite bath adsorption measurements were performed utilizing $10 \mathrm{mg} / \mathrm{mL}$ of BSA as a model protein. The Q fibrous samples were preconditioned with $20 \mathrm{mM}$ phosphate equilibration buffer ( $\mathrm{pH}$ 7.4) for 2-3 $\mathrm{h}$, and then, the samples were incubated with protein solution at room temperature for $6 \mathrm{~h}$ under mild conditions of $10 \mathrm{rpm}$. The exact amount of BSA adsorbed by the adsorbent was measured by the differences in the absorbance (A280) of BSA before and after incubation. The DBC at 10\% breakthrough for the BSA with Q fibrous adsorbent material was determined by frontal studies [52]. The packed Q fibrous columns ( $5 \mathrm{~mm}$ and $50 \mathrm{~mm}$ ) were mounted to an ÄKTA explorer 100 system and equilibrated by passing the Tris-HCl buffer ( $\mathrm{pH}$ 7.4). The DBC measurements were evaluated by saturating the column with $2 \mathrm{mg} / \mathrm{mL}$ of BSA solution at linear flow velocities of $75-600 \mathrm{~cm} / \mathrm{h}$ and then by monitoring the UV absorbance at $280 \mathrm{~nm}$. The BSA bound to the adsorbents was eluted using $20 \mathrm{mM}$ Tris- $\mathrm{HCl}$ buffer containing $1 \mathrm{M} \mathrm{NaCl}$. For determining DBC of the XK 50 fibrous column operated at $600 \mathrm{~cm} / \mathrm{h}$ flow rate, a QF150 biotech pump was applied, and the dead volume of the system was determined by acetone injection. The amount of BSA bound was determined using the $10 \%$ breakthrough volume $(V)$, column void volume $\left(V_{0}\right)$, initial BSA concentration $\left(C_{0}\right)$ and, finally, using either the dry weight of adsorbent $\left(\mathrm{W}_{\mathrm{g}}\right)$ or its column volume $(\mathrm{CV})$, as shown in Equation (4) $[20,53]$. 


$$
\mathrm{DBC}(\mathrm{mg} / \mathrm{mL})=C_{0} \times\left(V-V_{0}\right) / \mathrm{CV} \text { (or) } \mathrm{Wg}
$$

In another study, the effect of DBC at $10 \%$ breakthrough on the sample molecular weight was determined by loading separately low (BSA) and high (thyroglobulin) molecular weight proteins of $2 \mathrm{mg} / \mathrm{mL}$ concentration in a $1-\mathrm{mL}$ packed fibrous column (Tricorn 5/50) operated at a flow velocity of $300 \mathrm{~cm} / \mathrm{h}$.

\section{Results and Discussion}

\subsection{Physico-Chemical Characterization of the Adsorptive Material}

The adsorptive cellulose fiber utilized has undergone a chemical treatment to allow a rapid swelling of the adsorptive material from the dry state using buffer solution [20,47]. The swelling of cellulose fiber facilitates the disruption of the internal hydrogen bonds between polymer chains, which increases the polymer backbone accessibility to analytes. The cellulose fibers containing trimethyl ammonium ligand were investigated. Water uptake experiments revealed a $\sim 92 \%$ porosity, indicating that most of the water was able to freely move inside the fiber structure, allowing solute diffusion. The degree of swelling was observed as $3.95 \mathrm{~g} / \mathrm{g}$ in distilled water at $24{ }^{\circ} \mathrm{C}$, which was not suitable to avoid affecting the physical integrity of the material. The SEM images in Figure 1 shows the representative morphologies of (a) virgin cellulose fiber and (b) Q fibers. The modified fibers have an average diameter of 5-20 $\mu \mathrm{m}$ in the dry state and $\sim 20 \mu \mathrm{m}$ in the wet state. These values were obtained by qualitatively measuring the diameters of fibers from microscopy images. The overall morphology of the adsorptive Q fibers (Figure 1b), showed the same overall aspect as virgin cellulose fibers. An increase in fiber diameter can be appreciated, however, as the large diameter heterogeneity of this natural material cannot be quantified.
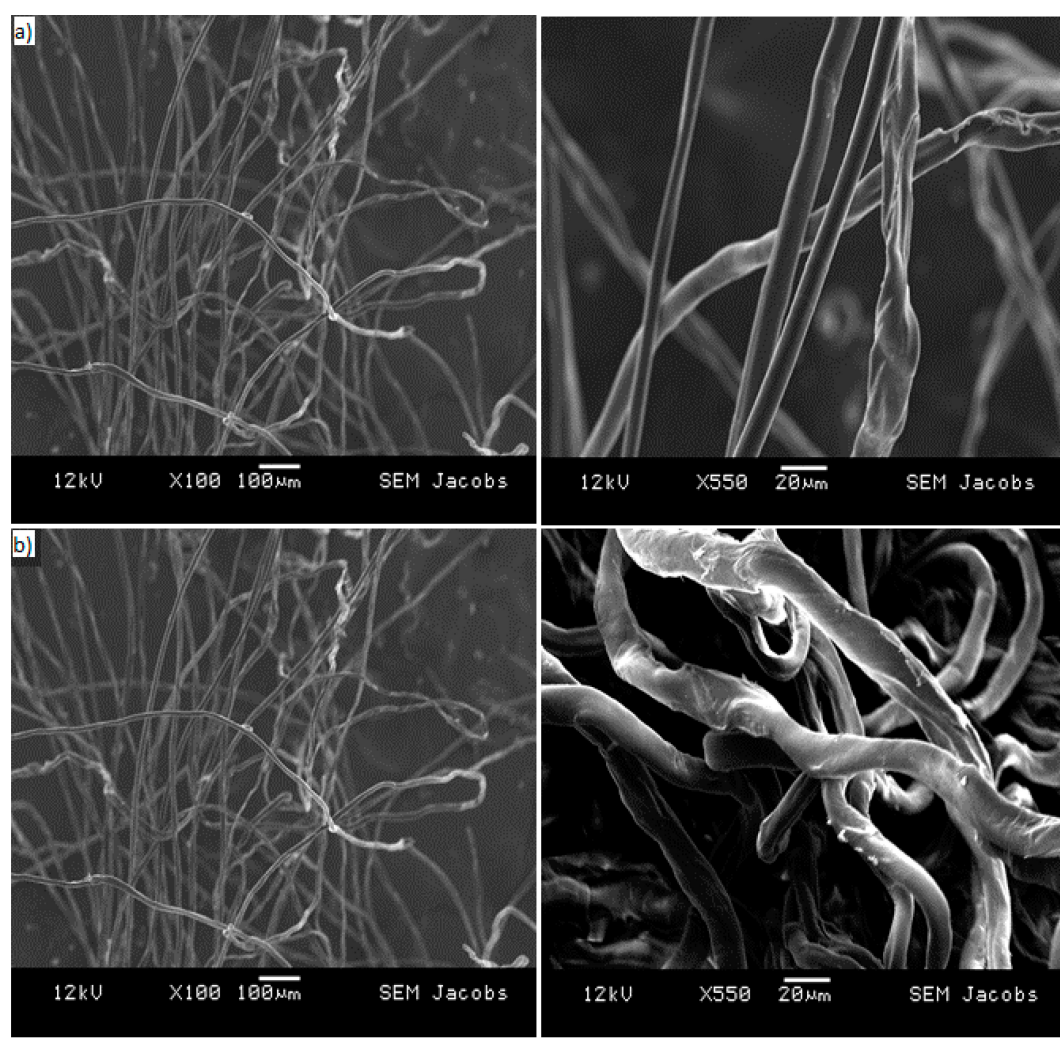

Figure 1. SEM images of (a) virgin cellulose fibers and (b) adsorptive $Q$ fibers at different scales. 
Figure 2 explains the confocal images of (a)-(c) of BSA (2 mg/mL) labeled with Alexa 488 fluorescent-stained representing the protein adsorption on the whole fiber and control images of (d)-(f) of non-labeled BSA at 488 that are $\sim 20 \mu \mathrm{m}$ in diameter. It had been noted that the Q fiber morphology in buffer can be pictured using CLSM at higher magnification; however, in such conditions, the complete profile cannot be obtained. The confocal microscopy studies revealed the distribution and high protein adsorption as a consequence of the protein penetration inside the fiber body, transformed in a hydrogel structure. A study of the flow-through property and protein binding of the fiber can be monitored with CSLM, which might give important information on the dynamic behavior of porous adsorbents during separation.

a)

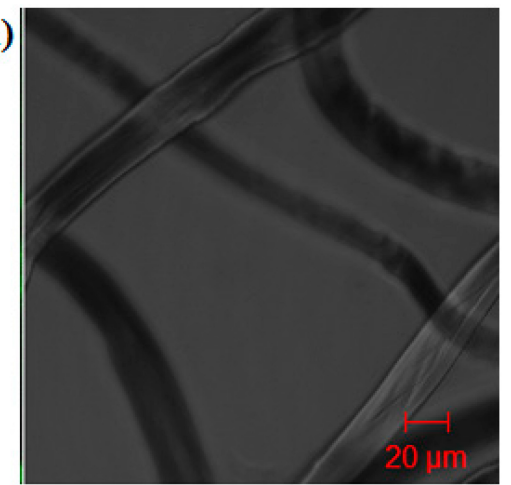

d)

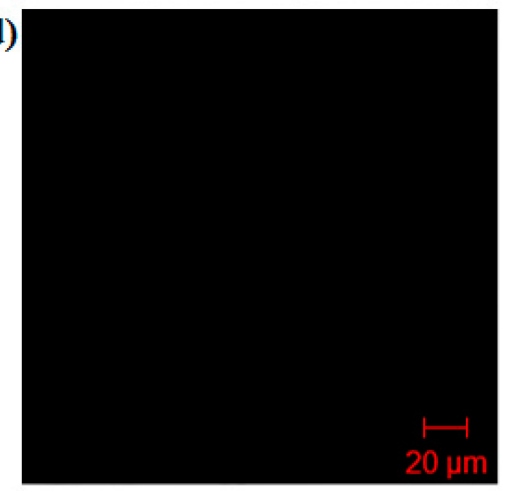

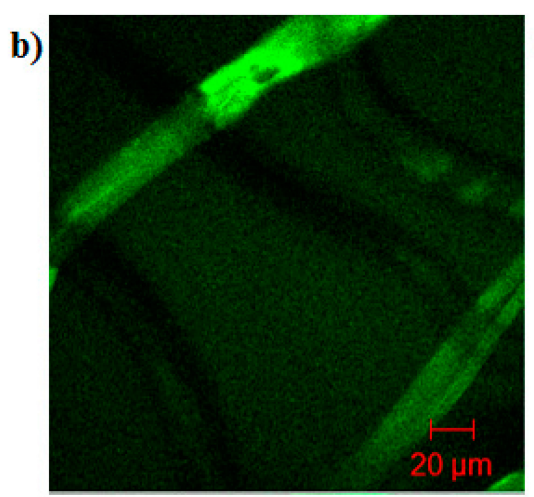

e)

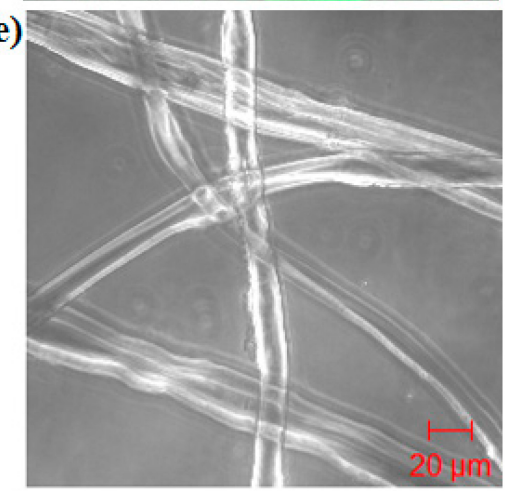

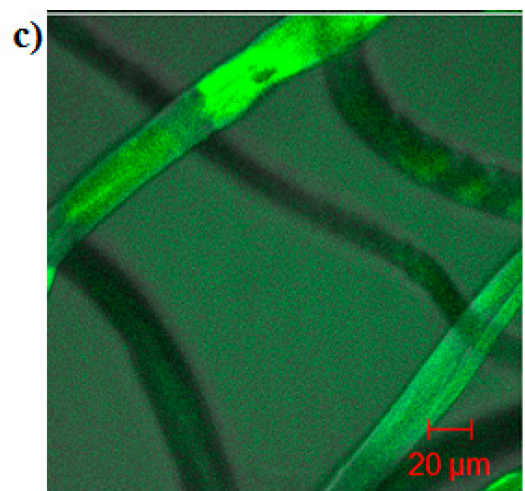

f)

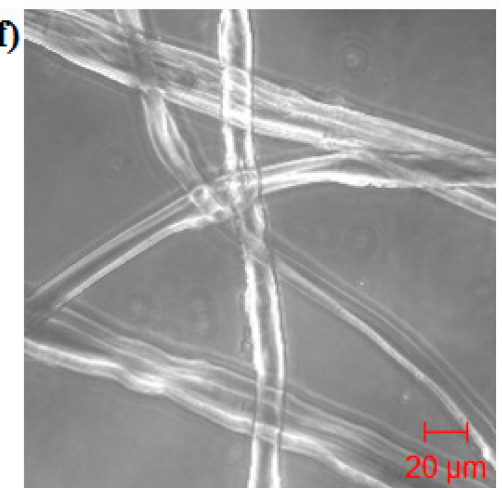

Figure 2. Confocal microscopy of Q fibers: (a) bright field, (b) fluorescence and (c) merged images of BSA labeled with Alexa Fluor 488 (green dye); and (d) bright field, (e) fluorescence and (f) merged images of non-labeled BSA at $488 \mathrm{~nm}$.

\subsection{Functional Characterization}

\subsubsection{Packing Efficiency}

The Q fibrous adsorbent as a chromatographic support in a packed column illustrates a relatively low dry packing density $(0.2 \mathrm{~g} / \mathrm{mL})$ due to its high swelling ratio [20]. The effect of packing heterogeneity may severely impede the separation efficiencies of the chromatography columns [54-57] that can be eliminated by swelling of the bed at a very low flow velocity $(75 \mathrm{~cm} / \mathrm{h})$ [20]. Figure 3 displays the relationship between the theoretical plate height $(\mathrm{H})$ and linear flow velocity of 5-mm inner diameter column randomly packed with Q fibers compared to Q Sepharose FF adsorbents. For the fibrous column, when the flow velocity was higher than $75 \mathrm{~cm} / \mathrm{h}$, the plate height only increased slightly and nearly reached a plateau with a flow velocity up to $600 \mathrm{~cm} / \mathrm{h}$, i.e., the plate height is nearly independent of flow 
velocity for a wide range of flow rates. This behavior contrasts conventional porous mediums, like Q Sepharose FF columns, for which the plate height is strongly dependent on flow velocity $[58,59]$. The resultant theoretical plate height $(\mathrm{H})(0.5-0.8 \mathrm{~mm})$ and the measured peak asymmetric $\left(\mathrm{A}_{\mathrm{s}}\right)$ values $(\leq 1.6)$ of the fibrous column demonstrated good packing efficiency with good reproducibility and were comparable to bead packed columns.

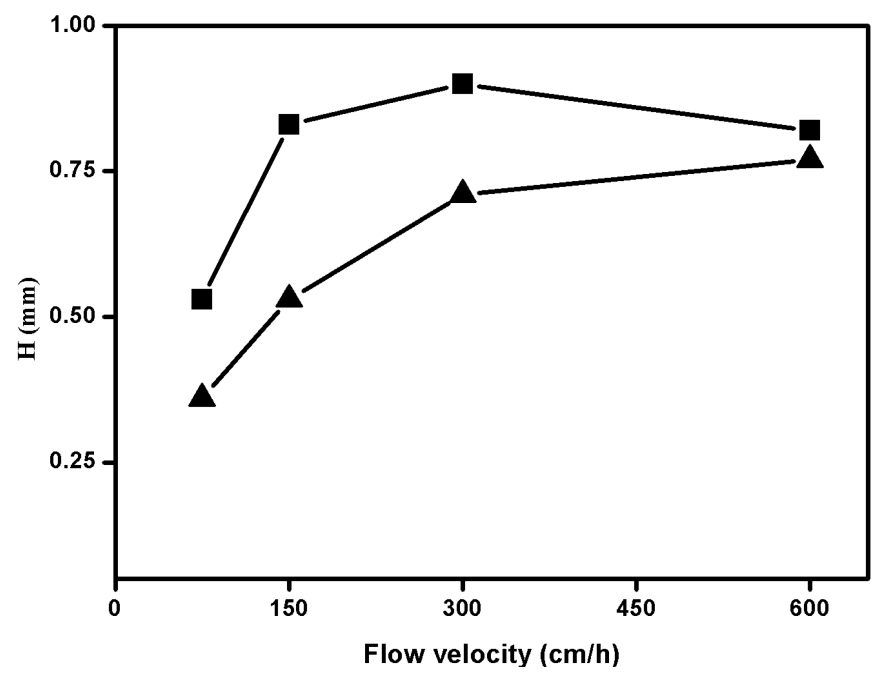

Figure 3. Theoretical plate height $(\mathrm{H})$ versus flow velocity. Mobile phase: $20 \mathrm{mM}$ phosphate buffer (pH 7.4). (घ) Q fibrous adsorbent; ( $\mathbf{\Delta})$ Q Sepharose FF beads. Conditions: column, $5 \mathrm{~mm}$ ID $\times 5.5 \mathrm{~cm} \mathrm{~L}$; sample: acetone $5 \%(v / v)$ of $1 \%$ column volume.

\subsubsection{Pulse Analysis to Determine Porosity Measurements}

The total and interstitial porosities of a packed column were measured by pulse experiments using first absolute moment analysis, which is expressed by the following equation:

$$
\mu_{1}=\frac{\int_{0}^{\infty} C(t) t d t}{\int_{0}^{\infty} C(t) d t}
$$

where $\mu_{1}$ is the first absolute moment, $C$ is the concentration of tracer $(\%)$ in the column and $t$ is time. The relationship between the first absolute moment and the total porosity $\varepsilon$ is given by the expression:

$$
\mu_{1}=\frac{L}{u_{0}} \varepsilon
$$

where $u_{0}$ is the superficial velocity and $\mathrm{L}$ is the height of the column. If $\mu_{1}$ is plotted versus $\mathrm{L} / u_{0}$, the slope of the curve is porosity. This technique was previously utilized using small injections of differently-sized tracers that were applied to the packed column under nonbinding conditions $[35,60]$. In this work, acetone was commonly used to determine total porosity, and the globular protein, lactoferrin, can be used to measure the interstitial porosity of a column packed with the Q fibrous adsorbent. Figure 4 represents the plot of the first absolute moments versus $\mathrm{L} / u_{0}$ for the two tracers. This has, presumably, shown that acetone is much smaller than lactoferrin, and the obtained experimental results indicate that acetone has a longer residence time and a larger slope when compared to the globular protein. This is 
due to the fact that the pores are more easily available for acetone and are inaccessible by lactoferrin. The porosity measured with acetone and lactoferrin was found to be 0.97 and 0.47 , respectively.

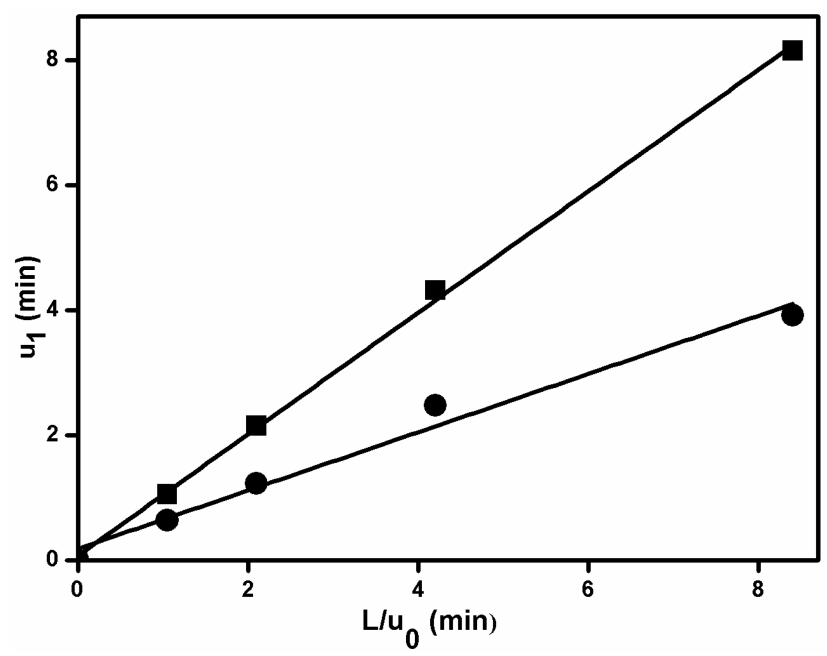

Figure 4. First moment versus $\mathrm{L} / \mathrm{u}_{0}$ for pulse injections of acetone and lactoferrin into a column packed with Q fibrous adsorbent.

\subsubsection{Pressure Drop Measurements}

The pressure drop in a porous medium follows Darcy's law at a low Reynolds number and is given by the expression [61]:

$$
u_{0}=\frac{k}{\mu} \frac{\Delta P}{L}
$$

where $u_{0}$ is the superficial velocity; $\mathrm{k}$ is the permeability coefficient; $\mu$ is the viscosity of the mobile phase, which is 0.01 poise for the phosphate buffer; $\Delta \mathrm{P}$ is pressure drop across the medium; and $\mathrm{L}$ is the height of the medium. The superficial velocity is plotted as a function of the measured $\mathrm{P} / \mathrm{L} \mu$ value for two different diameter columns packed with Q fiber material, as shown in Figure 5. The slope of the curves is the permeability coefficient, which is equal to $0.95 \times 10^{-7} \mathrm{~cm}^{2}$ and $1.51 \times 10^{-7} \mathrm{~cm}^{2}$ for the $5-\mathrm{mm}$ and 50-mm diameter columns, respectively. These obtained values are between one- and three-times greater than the literature values of membranes developed for similar purposes $[35,61]$ and between one- and two-times greater than the values of columns packed with ion exchange beads $[62,63]$. The pressure flow curves can also be accounted for until the critical flow velocity is reached, when the pressure drop rises to an extreme value; however, this needs further investigation due to the limitation of system compatibility. From the experimental results, it was recorded that the permeability coefficient value is not affected, even with increasing the column volume, which significantly showed well-preserved hydrodynamic characteristics. Several significant parameters, such as pore structure, shape, size, swelling degree and compatibility with the mobile phase, can change the back pressure of the column. 

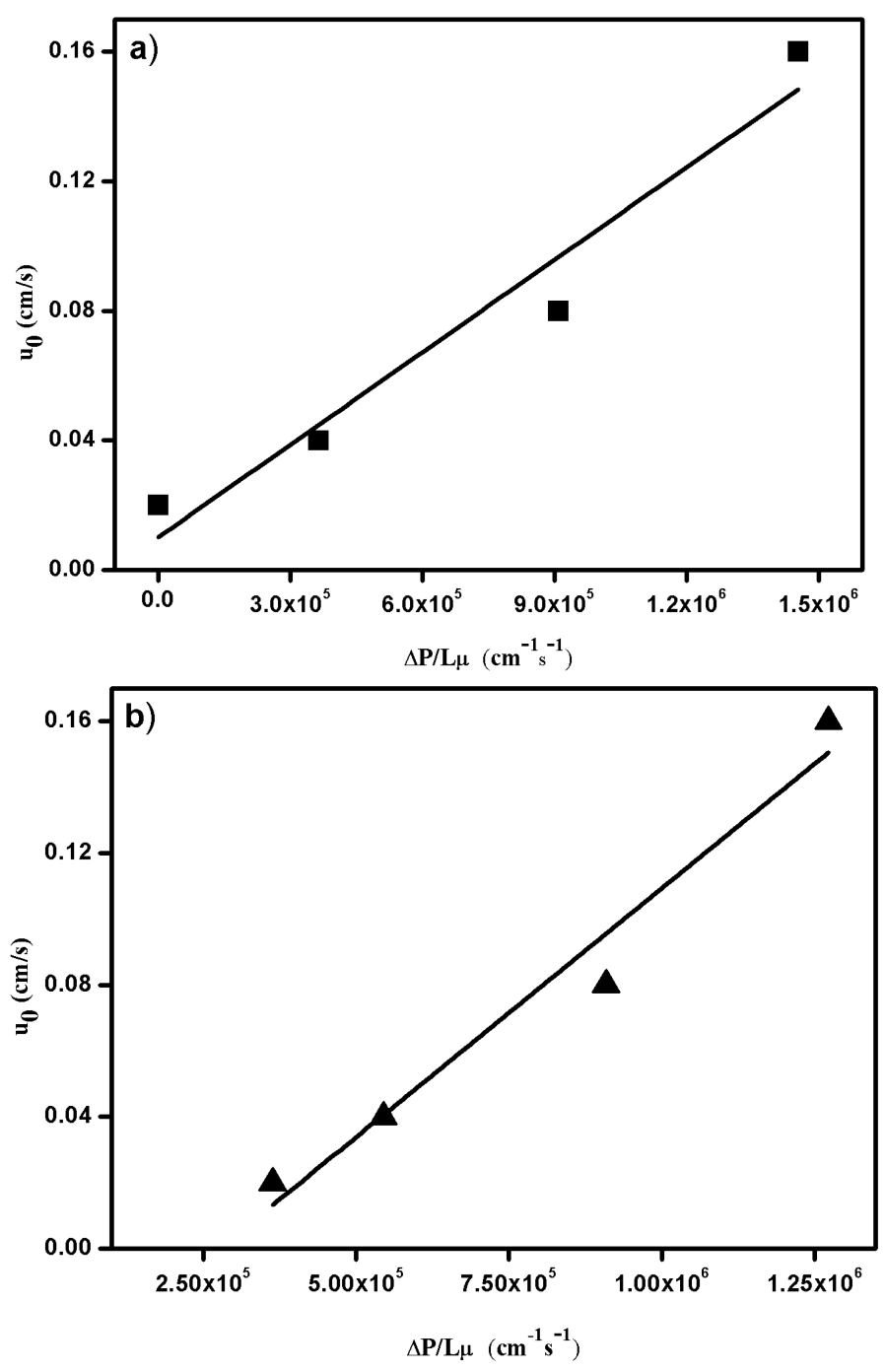

Figure 5. Superficial flow velocity versus pressure drop for a column packed with $Q$ fibrous adsorbent. (घ) $5 \mathrm{~mm} \mathrm{ID} \times 5.5 \mathrm{~cm} \mathrm{L-column} \mathrm{(a);} \mathrm{( \Delta )} 50 \mathrm{~mm} \mathrm{ID} \times 5.5 \mathrm{~cm} \mathrm{L-column} \mathrm{(b).}$

\subsubsection{Total Ionic Capacity}

The total ionic capacity of the $\mathrm{Q}$ fiber was determined by the $\mathrm{pH}$ transient method at a flow rate of $300 \mathrm{~cm} / \mathrm{h}$, and the value was found to be $0.51 \mathrm{mmol} / \mathrm{mL}$. The $\mathrm{pH}$ profile of the packed fibrous column is shown in Figure 6. Phosphate analysis was evaluated in the same manner with Q Sepharose FF, which showed an ionic capacity of $0.22 \mathrm{mmol} / \mathrm{mL}$. The resulting fibrous ionic capacity (phosphate) is higher than that of commercially available ion exchange adsorbents, as mentioned in the literature [64]. However, the strategy of built-in functions is known to produce proper modification of fibrous structures due to the optimization of chemical treatment with high numbers of charged groups on the ion exchangers. 


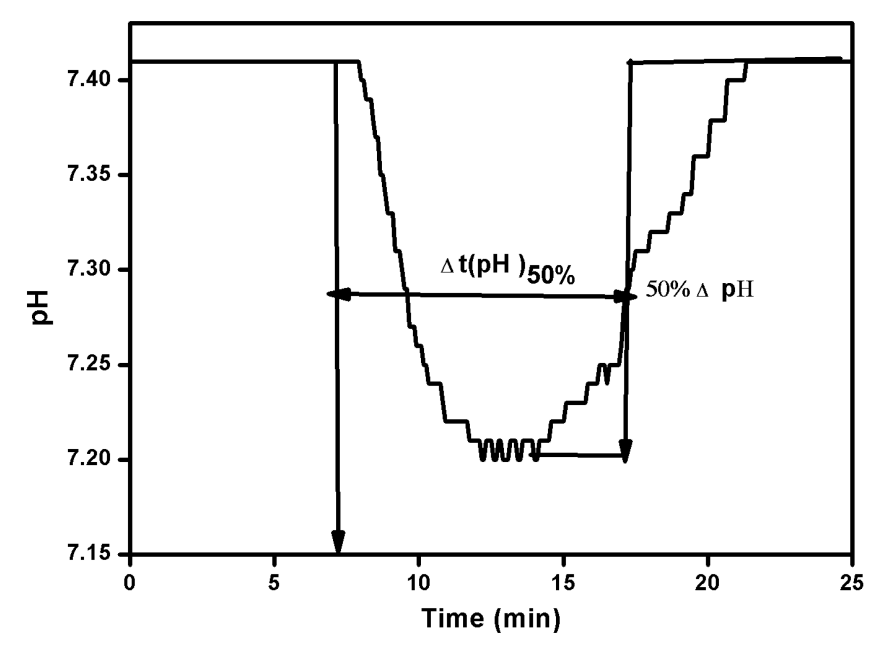

Figure 6. Determination of $\Delta \mathrm{t}(\mathrm{pH})_{50 \%}$ from the $\mathrm{pH}$ profile for the $\mathrm{Q}$ fibrous packed column. Conditions: Buffer A, $500 \mathrm{mM}$ phosphate, $\mathrm{pH}$ 7.4; Buffer B, $20 \mathrm{mM}$ phosphate, $\mathrm{pH}$ 7.4.; column $(5 \mathrm{~mm}$ ID $\times 5.5 \mathrm{~cm} \mathrm{~L})$. Method: $100 \%$ Buffer A $(8 \mathrm{~min})$ step to $100 \%$ Buffer B (24 min). Flow rate: $150 \mathrm{~cm} / \mathrm{h}$. Detection: $\mathrm{pH}$.

\subsection{Chromatography Performance}

BSA was selected as a model protein to illustrate concomitant mass transfer studies of the Q fibrous adsorbents in static and dynamic conditions. From the finite bath adsorption experiments, the static capacity of fiber was found to be $140 \mathrm{mg} / \mathrm{mL}$. The dynamic breakthrough analysis of any adsorption system is a combination of equilibrium binding capacity, adsorption kinetics and system dispersion [65], and the performance was evaluated via breakthrough curve analysis (BTC) as a function of superficial velocity. The results of the breakthrough (Table 1) experiments carried out in two columns of a different diameter, $5 \mathrm{~mm}$ and $50 \mathrm{~mm}$, at increasing flow rates as expressed by the quantities DBC are shown in Figure 7. The DBC values obtained at a flow rate of $300 \mathrm{~cm} / \mathrm{h}$ for $5-\mathrm{mm}$ and $50-\mathrm{mm}$ fibrous columns were $268 \mathrm{mg} / \mathrm{g},(53.6 \mathrm{mg} / \mathrm{mL})$ and $299 \mathrm{mg} / \mathrm{g}(59.8 \mathrm{mg} / \mathrm{mL})$, respectively. It has been observed that there is a linear scalability in the performance $(\sim 5 \mathrm{mg} / \mathrm{mL}$ deviation) of the fibrous columns at increasing flow rates with an increasing column volume. In another experiment, Q fibrous adsorbents showed nearly identical capacity at a slow flow rate of $75 \mathrm{~cm} / \mathrm{h}$ and relatively higher capacity compared to Q Sepharose FF with increasing flow rates, even up to $600 \mathrm{~cm} / \mathrm{h}$. The resultant values from Table 1 demonstrate that the fibrous adsorbent capacity is maintained and nearly independent of higher flow rates when compared to packed-bed beads where the capacity is reduced by half with an increase in flow rates [63]. The values reported are also higher compared to strong anion exchange monolithic adsorbents (30 mg/mL) of CIM-QA (BIA Separations, Villach, Austria) and $40 \mathrm{mg} / \mathrm{mL}$ for UNO-Q monoliths (Bio-Rad, Hercules, CA, USA) [66].

On the other hand, residence time distribution (RTD) analysis was performed to evaluate axial mixing. Response pulses obtained employing acetone as the tracer allowed for the determination of the Péclet number (Pe) using the tank in series model and the dispersion model [67] to fit the experimental data and interpreting the normalized profiles. The resultant Péclet number for Q fibrous support $(\geq 60)$ remained constant, suggesting plug flow characteristics with minimal axial mixing (see Figure 8) within the bed. However, a reduction of DBC at very high flow velocity can be explained by a small increase 
in axial dispersion within the system $[20,65]$. We speculate that the presence of a fiber entanglement may enhance the convective mass transfer and significantly reduce the stagnant zones by minimizing the diffusive distance [68]. Because the distance between the convective flow through pores (that is the length of diffusion path) was quite short (fiber radius), pore fusion did not play a significant role in affecting the column efficiency [69]. It has been noted that there was no column compaction at high ionic strength after the column was regenerated with $1 \mathrm{M} \mathrm{NaCl}$, and the fibrous column can be reused. The advantages of a higher binding under a dynamic regime at higher flow rates for fibrous adsorbent were even more evident by having good dispersion and adsorption, thereby suggesting that there could be a potential use for additional adsorbents for bioprocess applications compared to classical packed-bead columns.

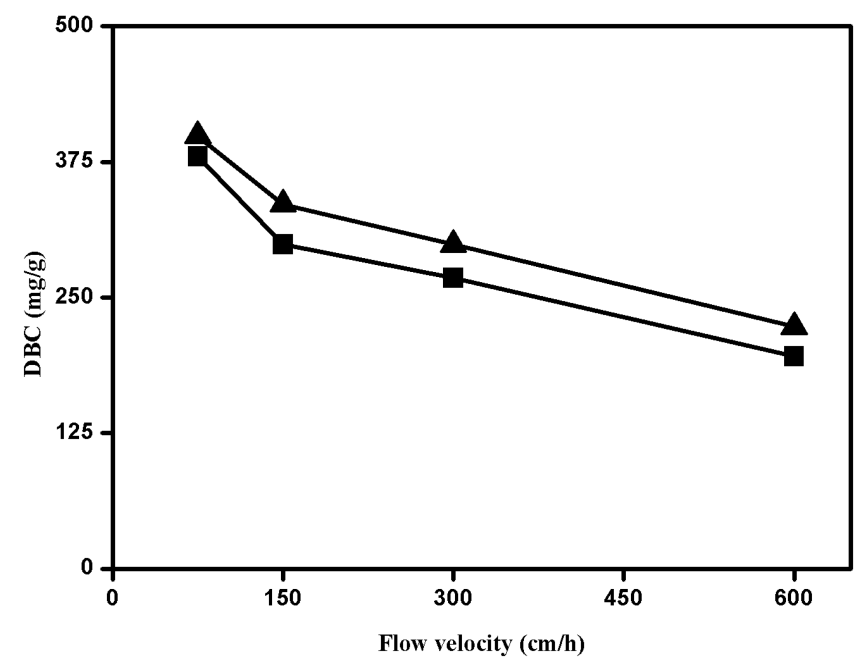

Figure 7. Dynamic binding capacity versus flow velocity for two different diameter columns packed with Q fibrous adsorbent at four different flow rates $(75,150,300$ and $600 \mathrm{~cm} / \mathrm{h})$. Conditions: $20 \mathrm{mM}$ phosphate buffer, $\mathrm{pH} 7.4$, was used as the equilibration buffer, and the sample (BSA $2 \mathrm{mg} / \mathrm{mL}$ ) was dissolved in running buffer. (•) Column: $5 \mathrm{~mm}$ ID $\times 5.5 \mathrm{~cm} \mathrm{~L}$; ( $\Delta$ ) column: $50 \mathrm{~mm} \mathrm{ID} \times 5.5 \mathrm{~cm} \mathrm{~L}$.

Table 1. Comparison of binding capacities under static and dynamic conditions of anion exchange adsorbents.

\begin{tabular}{ccccc}
\hline \multirow{2}{*}{ Adsorbents } & \multicolumn{4}{c}{ DBC at 10\% Breakthrough $\mathbf{( m g} / \mathbf{m L})$} \\
\cline { 2 - 5 } & $\mathbf{7 5} \mathbf{~ c m} / \mathbf{h}$ & $\mathbf{1 5 0} \mathbf{~ c m} / \mathbf{h}$ & $\mathbf{3 0 0} \mathbf{~ c m} / \mathbf{h}$ & $\mathbf{6 0 0} \mathbf{~ c m} / \mathbf{h}$ \\
\hline Q fibers & $76 \pm 2$ & $59 \pm 2$ & $53 \pm 2$ & $39 \pm 2$ \\
Q Sepharose FF & $82 \pm 2$ & $37 \pm 2$ & $32 \pm 2$ & $22 \pm 2$ \\
\hline
\end{tabular}

Two-milligrams per milliliter solutions of BSA were used for dynamic binding capacity (DBC) measurement with a 1-mL column volume (column: $5 \mathrm{~mm}$ ID $\times 5.5 \mathrm{~cm} \mathrm{~L}$ ), while $10-\mathrm{mg} / \mathrm{mL}$ solutions of BSA were applied for finite bath experiments. The capacity reported (GE Healthcare application note) for Q Sepharose FF was reported $110 \mathrm{mg} / \mathrm{mL}$ for human serum albumin (HSA) at a flow velocity of $75 \mathrm{~cm} / \mathrm{h}$. 


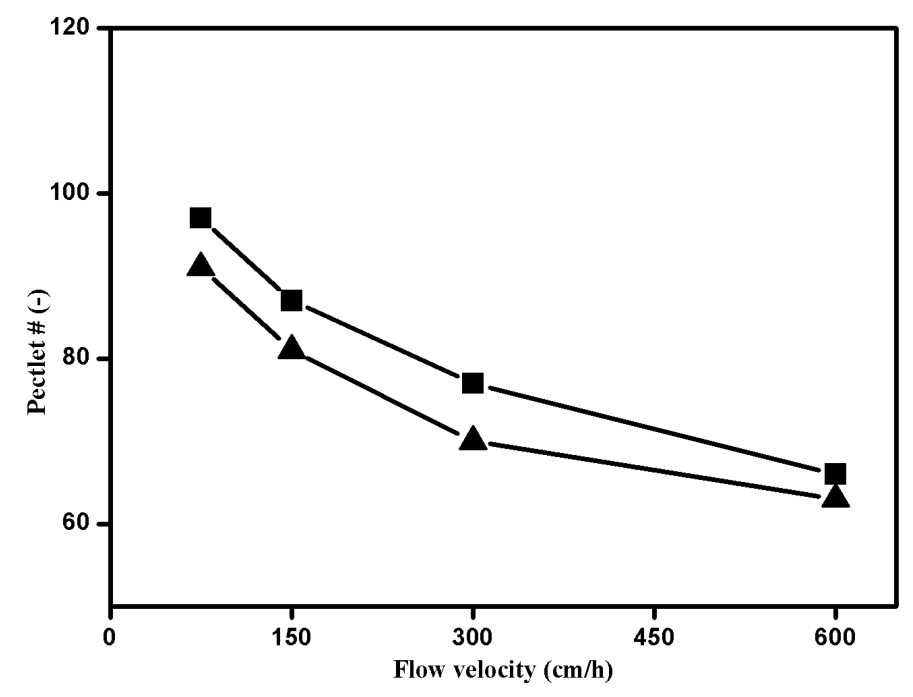

Figure 8. Péclet number at four different flow rates for the anion exchange fibrous adsorbent. Mobile phase: $20 \mathrm{mM}$ phosphate buffer (pH 7.4). Conditions: (匹) column, $5 \mathrm{~mm} \mathrm{ID} \times 5.5 \mathrm{~cm} \mathrm{~L}$; ( $\Delta$ ) column, $50 \mathrm{~mm}$ ID $\times 5.5 \mathrm{~cm} \mathrm{~L}$. Sample acetone $(5 \%$ of $v / v)$ of $1 \%$ column volume.

\subsection{Effect of Molecular Weight of the Sample on the DBC}

Figure 9 shows the results of breakthrough curves of low and high molecular weight proteins (BSA - 66.5 kDa; thyroglobulin — $650 \mathrm{kDa}$ ) against normalized sample concentration, respectively. The breakthrough at $10 \%$ saturation for the thyroglobulin was low $(6 \mathrm{mg} / \mathrm{mL})$ when compared to BSA, which indicates that the anion exchange fibrous adsorbent has the same behavior for DBC as hydrogel-bead adsorbents for high molecular weight proteins. However, the DBC for thyroglobulin results in being almost two-times higher than for the corresponding commercial Q Sepharose FF resins [64]. These experiments illustrate that the $\mathrm{Q}$ fibers have a significant improvement in the binding capacity for samples having molecular weight proteins up to $650 \mathrm{kDa}$.

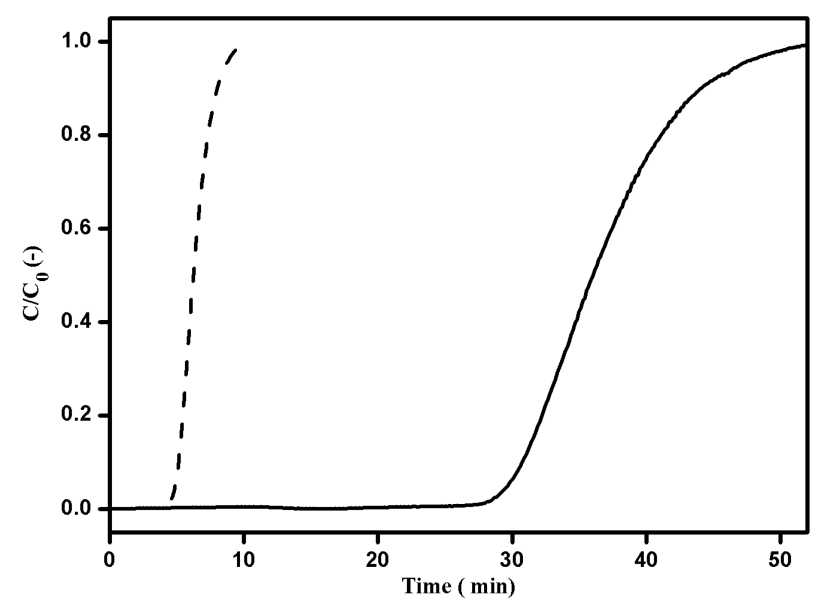

Figure 9. Breakthrough curves in terms of sample volume for (-) BSA and (---) thyroglobulin on $\mathrm{Q}$ fibrous adsorbent packed in a column $(5 \mathrm{~mm}$ ID $\times 5.5 \mathrm{~cm} \mathrm{~L})$. Conditions: $20 \mathrm{mM}$ phosphate buffer, $\mathrm{pH} 7.4$, was used as the equilibration buffer, and the sample $(2 \mathrm{mg} / \mathrm{mL})$ was dissolved in running buffer. 


\section{Conclusions}

The performance of an anion exchange fibrous adsorbent based on cellulose fiber has been evaluated as a chromatography support. Results from microscopy studies indicated that the fiber morphology was well retained in the adsorptive material compared to virgin cellulose fibers. The potential of fibrous column packing efficiency and flow permeability were evaluated for two different linear scalable columns and achieved reproducible column-to-column packing homogeneity and a high permeability coefficient compared to other membrane types and to packed beds of chromatographic resins. The results of the pulse experiments show that the modified fibrous supports maintain very high porosity for both small and large solutes and have interstitial porosities greater than typical bead packed beds. For the column characteristics of the packed fibers, breakthrough analyses have been determined for the operation in the frontal mode and also comparing the effect of $\mathrm{DBC}$ on the nature of the sample. The results from protein adsorption studies show that the fibrous adsorbents have high binding capacities under static and dynamic conditions and, more significantly, have the ability to bind high molecular weight proteins. This research describes the performance of the fibrous adsorbent as a chromatography media in terms of high binding capacity at higher operational flow rates that can be linearly scalable from a 1-mL to $110-\mathrm{mL}$ column volume. Dynamic breakthrough experiments of the fibrous adsorbents indicate that high binding capacities can be achieved with higher flow permeabilities than commercial columns of ion exchange resin with similar or higher capacities. The main advantage of this fibrous adsorption system from an industrial perspective is utilizing the materials in their original structure, without changing the physico-chemical transformation of the material shape, but having an important swelling behavior that improves the adsorptive capacity of the material. In summary, all of these results support that packed fibrous adsorbents have great potential for high throughput and high binding capacity in the separation and purification of biotherapeutics and may also become an attractive alternative to replace other types of resins, membranes and particles currently being used in the biopharmaceutical industry. Additionally, this fiber material offers the opportunity to develop disposable bioseparation devices due to the inexpensiveness of the raw material, low production cost and competitive process parameters.

\section{Acknowledgments}

This work is financially supported by the European Union Seventh Framework Programme (FP7/2007-2013) under Grant Agreement No. 312004. The authors are grateful for the support of the Downstream BioProcessing Laboratory members from the School of Engineering and Sciences at Jacobs University Bremen gGmbH.

\section{Author Contributions}

P.R.G. and M.F.L. have designed the work. P.R.G. carried out the experiments and wrote the manuscript. N.S.B. and M.L.S. contributed for the microscopic analysis of the fibers. M.G. and M.F.L. reviewed the manuscript critically. All the authors have read the article and approved the final manuscript.

\section{Conflicts of Interest}

The authors declare no conflict of interest. 


\section{References}

1. Dainiak, M.B.; Kumar, A.; Plieva, F.M.; Galaev, I.Y.; Mattiasson, B. Integrated isolation of antibody fragments from microbial cell culture fluids using supermacroporous cryogels. J. Chromatogr. A 2004, 1045, 93-98.

2. Low, D.; O'Leary, R.; Pujar, N.S. Future of antibody purification. J. Chromatogr. B 2007, 848, $48-63$.

3. Suzanne, S.F. Process economics of industrial monoclonal antibody manufacture. J. Chromatogr. B 2007, 848, 8-18.

4. Banik, R.; Santhiagu, A.; Kanari, B.; Sabarinath, C.; Upadhyay, S. Technological aspects of extractive fermentation using aqueous two-phase systems. World J. Microbiol. Biotechnol. 2003, 19, 337-398.

5. Gottschalk, U. Comprehensive Biotechnology; Academic Press: Waltham, MA, USA, 2011; Volume 3.

6. Gottschalk, U. Bioseparation in antibody manufacturing: The good, the bad and the ugly. Biotechnol. Prog. 2008, 24, 496-503.

7. Gottschalk, U. 3.57-Overview of downstream processing in the biomanufacturing industry. In Comprehensive Biotechnology, 2nd ed.; Moo-Young, M., Ed.; Academic Press: Waltham, MA, USA, 2011; pp. 669-682.

8. Przybycien, T.M.; Pujar, N.S.; Steele, L.M. Alternative bioseparation operations: Life beyond packed-bed chromatography. Curr. Opin. Biotechnol. 2004, 15, 469-478.

9. Andrew, L. Process chromatography: Current constraints and future options for the adsorptive recovery of bioproducts. Curr. Opin. Biotechnol. 2002, 13, 95-103.

10. Hubbuch, J.; Kula, M.R. Isolation and purification of biotechnological products. J. Non-Equilib. Thermodyn. 2007, 32, 99-127.

11. D’Souza, R.N.; Azedo, A.M.; Aires-Barros, R.; Krajnc, N.L.; Kramberger, P.; Carbajal, M.L.; Grasselli, M.; Meyer, R.; Fernández-Lahore, M. Emerging technologies for the integration and intensification of downstream bioprocesses. Pharm. Bioprocess. 2013, 1, 423-440.

12. Lightfoot, E.N.; Moscariello, J.S. Bioseparations. Biotechnol. Bioeng. 2004, 87, 259-273.

13. Guiochon, G. Preparative liquid chromatography. J. Chromatogr. A 2002, 965, 129-161.

14. Levison, P.R. Large-scale ion-exchange column chromatography of proteins. Comparison of different formats. J. Chromatogr. B 2003, 790, 17-33.

15. Ghosh, R. Protein separation using membrane chromatography: Opportunities and challenges. J. Chromatogr. A 2002, 952, 13-27.

16. Charcosset, C. Review: Purification of proteins by membrane chromatography. J. Chem. Technol. Biotechnol. 1998, 71, 95-110.

17. Thömmes, J.; Kula, M.R. Membrane chromatography? An integrative concept in the downstream processing of proteins. Biotechnol. Prog. 1995, 11, 357-367.

18. Boi, C.; Facchini, R.; Sorci, M.; Sarti, G.C. Characterisation of affinity membranes for IgG separation. Euromembrane 2006, 199, 544-546.

19. Boi, C.; Dimartino, S.; Sarti, G.C. Performance of a new protein affinity membrane for the primary recovery of antibodies. Biotechnol. Prog. 2008, 24, 640-647. 
20. Gavara, P.R.; Cabrera, R.; Vennapusa, R.R.; Grasselli, M.; Fernandez-Lahore, M. Preparation, characterization, and process performance of composite fibrous adsorbents as cation exchangers for high throughput and high capacity bioseparations. J. Chromatogr. B 2012, 903, 14-22.

21. Singh, N.K.; Dsouza, R.N.; Grasselli, M.; Fernandez-Lahore, M. High capacity cryogel-type adsorbents for protein purification. J. Chromatogr. A 2014, 1355, 143-148.

22. Hutten, I.M. Handbook of Nonwoven Filter Media; Butterworth-Heinemann: Burlington, MA, USA, 2007.

23. Ruixia, L.; Hongxiao, G.J.T. Adsorption of fluoride, phosphate, and arsenate ions on a new type of ion exchange fiber. J. Colloid Interface Sci. 2002, 248, 268-274.

24. Gong, B.L.; Li, X.Q.; Wang, F.R.; Xu, H.D.; Chang, X.J. Synthesis of polyacrylacylaminourea chelating fiber and properties of concentration and separation of trace metal ions from samples. Anal. Chim. Acta 2001, 427, 287-291.

25. Jaskari, T.; Vuorio, M.; Kontturi, K.; Manzanares, J.A.; Hirvonen, J. Ion-exchange fibers and drugs: An equilibrium study. J. Control. Release 2001, 70, 219-229.

26. Wen, B.; Shan, X.Q.; Liu, R.X.; Tang, H.X. Preconcentration of trace elements in sea water with poly (acrylaminophosphonic-dithiocarbamate) chelating fiber for their determination by inductively coupled plasma mass spectrometry. Fresen. J. Anal. Chem. 1999, 363, 251-255.

27. Motobu, M.; Matsuo, S.; Wang, P.C.; Kataoka, H.; Matsumura, M. High renin productivity of rcho cells cultivated in radial-flow nonwoven fabric mat packed-bed reactor with increasing circulating flow rate. J. Ferment. Bioeng. 1997, 83, 443-450.

28. Chen, C.; Huang, Y.L.; Yang, S.T. A fibrous-bed bioreactor for continuous production of developmental endothelial locus-1 by osteosarcoma cells. J. Biotechnol. 2002, 97, 23-39.

29. Shukla, S.R.; Athalye, A.R. Mechanical and thermal-properties of glycidyl methacrylate grafted cotton cellulose. J. Appl. Polym. Sci. 1995, 57, 983-988.

30. Sokker, H.H.; Badawy, S.M.; Zayed, E.M.; Eldien, F.A.N.; Farag, A.M. Radiation-induced grafting of glycidyl methacrylate onto cotton fabric waste and its modification for anchoring hazardous wastes from their solutions. J. Hazard. Mater. 2009, 168, 137-144.

31. Harris, J.A.; Arthur, J.C. Radiation-initiated graft copolymerization of binary monomer mixtures containing acrylonitrile with cotton cellulose. J. Appl. Polym. Sci. 1970, 14, 3113-3128.

32. Brandt, S.; Goffe, R.A.; Kessler, S.; O-Conner, J.L.; Zale, S.E. Membrane based affin- ity technology for commercial scale purifications. Biotechnology 1988, 6, 779-782.

33. Boi, C.; Busini, V.; Salvalaglio, M.; Cavallotti, C.; Sarti, G.C. Understanding ligand-protein interactions in affinity membrane chromatography for antibody purification. J. Chromatogr. A 2009, 1216, 8687-8696.

34. Zhang, L.F.; Menkhaus, T.J.; Fong, H. Fabrication and bioseparation studies of adsorptive membranes/felts made from electrospun cellulose acetate nanofibers. J. Membr. Sci. 2008, 319 , 176-184.

35. Zheng, Y.; Liu, H.Y.; Gurgel, P.V.; Carbonell, R.G. Polypropylene nonwoven fabrics with conformal grafting of poly(glycidyl methacrylate) for bioseparations. J. Membr. Sci. 2010, 364, 362-371.

36. Li, C.H.; Ladisch, C.M.; Yang, Y.Q.; Hendrickson, R.; Keim, C.; Mosier, N.; Ladisch, M.R. Optimal packing characteristics of rolled, continuous stationary-phase columns. Biotechnol. Prog. 2002, 18, 309-316. 
37. Hamaker, K.; Rau, S.L.; Hendrickson, R.; Liu, J.; Ladisch, C.M.; Ladisch, M.R. Rolled stationary phases: Dimensionally structured textile adsorbents for rapid liquid chromatography of proteins. Ind. Eng. Chem. Res. 1999, 38, 865-872.

38. Shukla, S.R.; Athalye, A.R. Graft-copolymerization of glycidyl methacrylate onto cotton cellulose. J. Appl. Polym. Sci. 1994, 54, 279-288.

39. King, J.K.; Pinto, N.G. Short fibrous supports for preparative chromatographic separations of biomolecules. J. Chromatogr. 1992, 609, 61-68.

40. Singh, A.; Pinto, N.G. Polymeric short-fiber chromatographic supports for downstream processing of biomolecules. React. Polym. 1995, 24, 229-242.

41. Bondar, Y.; Kim, H.J.; Yoon, S.H.; Lim, Y.J. Synthesis of cation-exchange adsorbent for anchoring metal ions by modification of poly(glycidyl methacrylate) chains grafted onto polypropylene fabric. React. Funct. Polym. 2004, 58, 43-51.

42. Ma, Z.; Ramakrishna, S. Electrospun regenerated cellulose nanofiber affinity membrane functionalized with protein a/g for IgG purification. J. Membr. Sci. 2008, 319, 23-28.

43. Kaur, S.; Ma, Z.; Gopal, R.; Singh, G.; Ramakrishna, S.; Matsuura, T. Plasma-induced graft copolymerization of poly(methacrylic acid) on electrospun poly(vinylidene fluoride) nanofiber membrane. Langmuir 2007, 23, 13085-13092.

44. Blessing, T.; Remy, J.S.; Behr, J.P. Template oligomerization of DNA-bound cations produces calibrated nanometric particles. J. Am. Chem. Soc. 1998, 120, 8519-8520.

45. Nakamae, K.; Nizuka, T.; Miyata, T.; Furukawa, M.; Nishino, T.; Kato, K.; Inoue, T.; Hoffman, A.S.; Kanzaki, Y. Lysozyme loading and release from hydrogels carrying pendant phosphate groups. J. Biomater. Sci. Polym. Ed. 1997, 9, 43-53.

46. Jung, T.; Kamm, W.; Breitenbach, A.; Klebe, G.; Kissel, T. Loading of tetanus toxoid to biodegradable nanoparticles from branched poly(sulfobutyl-polyvinyl alcohol)-g-(lactide-co-glycolide) nanoparticles by protein adsorption: A mechanistic study. Pharm. Res. 2002, 19, 1105-1113.

47. Fernandez-Lahore, M.; Mariano, G. Composite Material. U.S. Patent No. 20,130,112,623, 9 May 2013.

48. Bibi, N.S.; Gavara, P.R.; Espinosa, S.L.S.; Grasselli, M.; Fernandez-Lahore, M. Synthesis and performance of 3d-megaporous structures for enzyme immobilization and protein capture. Biotechnol. Prog. 2011, 27, 1329-1338.

49. Plieva, F.M.; Savina, I.N.; Deraz, S.; Andersson, J.; Galaev, I.Y.; Mattiasson, B. Characterization of supermacroporous monolithic polyacrylamide based matrices designed for chromatography of bioparticles. J. Chromatogr. B 2004, 807, 129-137.

50. Lendero, N.; Vidič, J.; Brne, P.; Frankovič, V.; Štrancar, A.; Podgornik, A. Characterization of ion exchange stationary phases via ph transition profiles. J. Chromatogr. A 2008, 1185, 59-70.

51. Lendero, N.; Vidic, J.; Brne, P.; Podgornik, A.; Strancar, A. Simple method for determining the amount of ion-exchange groups on chromatographic supports. J. Chromatogr. A 2005, 1065, 29-38.

52. Boschetti, E.J.L.C. Enhanced diffusion chromatography and related sorbents for biopurification. In Bioseparation and Bioprocessing; Wiley-VCH Verlag GmbH: Weinheim, Germany, 2008.

53. Bibi, N.S.; Singh, N.K.; Dsouza, R.N.; Aasim, M.; Fernandez-Lahore, M. Synthesis and performance of megaporous immobilized metal-ion affinity cryogels for recombinant protein capture and purification. J. Chromatogr. A 2013, 1272, 145-149. 
54. Schure, M.R.; Maier, R.S. How does column packing microstructure affect column efficiency in liquid chromatography? Role Theory Chromatogr. 2006, 1126, 58-69.

55. Guiochon, G.; Sarker, M. Consolidation of the packing material in chromatographic columns under dynamic axial compression. I. Fundamental study. J. Chromatogr. A 1995, 704, 247-268.

56. Koh, J.-H.; Broyles, B.S.; Guan-Sajonz, H.; Hu, M.Z.C.; Guiochon, G. Consolidation and column performance of several packing materials for liquid chromatography in a dynamic axial compression column. J. Chromatogr. A 1998, 813, 223-238.

57. Herigstad, M.O.; Gurgel, P.V.; Carbonell, R.G. Transport and binding characterization of a novel hybrid particle impregnated membrane material for bioseparations. Biotechnol. Prog. 2011, 27 , 129-139.

58. Sun, G.Y.; Shi, Q.H.; Sun, Y. Novel biporous polymeric stationary phase for high-speed protein chromatography. J. Chromatogr. A 2004, 1061, 159-165.

59. Shi, Y.; Sun, Y. Fabrication and characterization of a novel biporous spherical adsorbent for protein chromatography. Chromatographia 2003, 57, 29-35.

60. Arnold, F.H.; Blanch, H.W.; Wilke, C.R. Analysis of affinity separations ii: The characterization of affinity columns by pulse techniques. Chem. Eng. J. 1985, 30, B25-B36.

61. Bird, R.B.; Stewart, W.E.; Lightfoot, E.N. Transport Phenomena; Wiley: New York, NY, USA, 2002; Volume 2.

62. Keener, R.N., Ш; Fernandez, E.J.; Maneval, J.E.; Hart, R.A. Advancement in the modeling of pressure-flow for the guidance of development and scale-up of commercial-scale biopharmaceutical chromatography. J. Chromatogr. A 2008, 1190, 127-140.

63. Du, K.-F.; Yan, M.; Wang, Q.-Y.; Song, H. Preparation and characterization of novel macroporous cellulose beads regenerated from ionic liquid for fast chromatography. J. Chromatogr. A 2010, 1217, 1298-1304.

64. Amersham Biosciences. Bioprocess media. In Sepharose Fast Flow Ion Exchangers; Amersham Biosciences: Uppsala, Sweden, 2003.

65. Garcia, M.C.; Marina, M.L.; Torre, M. Perfusion chromatography: An emergent technique for the analysis of food proteins. J. Chromatogr. A 2000, 880, 169-187.

66. Iberer, G.; Hahn, R.; Jungbauer, A. Monoliths as stationary phases for separating biopolymers-Fourth-generation chromatography sorbents. LC GC N. Am. 1999, 17, 998-1005.

67. Gutsche, R.; Bunke, G. Modelling the liquid-phase adsorption in packed beds at low reynolds numbers: An improved hydrodynamic model. Chem. Eng. Sci. 2008, 63, 4203-4217.

68. Afeyan, N.B.; Fulton, S.P.; Regnier, F.E. Perfusion chromatography packing materials for proteins and peptides. J. Chromatogr. 1991, 544, 267-279.

69. Svec, F.; Frechet, J.M.J. Molded rigid monolithic porous polymers: An inexpensive, efficient, and versatile alternative to beads for the design of materials for numerous applications. Ind. Eng. Chem. Res. 1999, 38, 34-48.

(C) 2015 by the authors; licensee MDPI, Basel, Switzerland. This article is an open access article distributed under the terms and conditions of the Creative Commons Attribution license (http://creativecommons.org/licenses/by/4.0/). 